\title{
Power output enhancement of grid-connected PV system using dual-axis tracking
}

\author{
Mohammed H.R. Alktranee ${ }^{1, *}$, Qudama Al-Yasiri ${ }^{2}$, and Mortda. M. Sahib ${ }^{1}$ \\ ${ }^{1}$ Department of Mechanics, Technical Institute of Basra, Southern Technical University, Basra, Iraq \\ 2 Mechanical Engineering Department, College of Engineering, University of Misan, Misan, Iraq
}

Received: 2 December 2019 / Received in final form: 30 January 2020 / Accepted: 30 January 2020

\begin{abstract}
The current paper proposes an augmentation of power output production of a single-phase gridconnected photovoltaic (PV) system using dual-axis solar tracking (DAST). Solarius PV software was applied to design and predict the energy demand for a single-family house over one year under the climate condition of Basra city, Iraq. The performance of the DAST-PV system was compared to another stationary PV system has the same capacity in terms of power output and the reduction of generated emissions over 20 years lifetime. The results showed that the stationary PV system can overcome up to $84.8 \%$ of the total electricity demand of the house while DAST-PV system can overcome up to $100 \%$ with surplus energy of $9886.55 \mathrm{kWh}$. Moreover, the greenhouse gases (GHGs) emissions avoided by the DAT-PV system were about $34.8 \%$ more than the stationary system over the system lifetime.
\end{abstract}

\section{Introduction}

In recent years, many countries worldwide tend to produce electricity utilizing various renewable sources such as nuclear, hydro, solar energy, etc. for several economic and environmental considerations. Solar PV technology showed rapid progress and has a significant role in green energy applications, especially in residential, agricultural and industrial applications. The PV industry for residential-sized scale has grown rapidly mainly due to the high drop of total costs from about $\$ 40,000$ in 2010 to roughly $\$ 18,000$ today [1]. Such reduction of the PV system cost is highly encouraging the developing countries, like Iraq, to adapt such green technology. Iraq has an excellent solar energy potential with long sunshine hours during the year but still lags away in the electrical power sector due to the continuous governmental corruption and the rely on the traditional power generation technologies. The thinking in a sustainable way about adapting the PV technology for electric power generation has researched in Iraq and showed excellent outcomes compared to the governmental national grid which relies on fossil fuel sources $[2,3]$.

\footnotetext{
* e-mail: mohammed.hr@stu.edu.iq
}

In general, the major issue may face the PV systems is the reduction of energy yield due to several factors such as the fluctuating of solar radiation, partial shading, orientation, dust and bird droppings, thus, it is very important to adopt techniques that could improve the energy yield of the PV system. Furthermore, the extracted power by the PV system is also affected by the conversion efficiency of the PV system components which may reduce the final power output by up to $25 \%$ which leads to lower the power output of the PV system more and more.

Many studies and developments were applied to achieve an effective increase in the efficiency of the PV system using different methods. The single vertical tracking system contributed to increasing the power output yield by up to $40 \%$ [4], while the dual-axis solar tracking system is one of the best solutions for power maximizing [5]. Tracking technique of PV panels is one of the recommended solutions that significantly contribute to increase the efficiency and capacity of the PV system. A DAST system was designed and implemented to improve the efficiency of 10W PV panel compared to a stand-alone PV system. The results showed improvement of up to $30 \%$ in the modified system [6]. A predictive control algorithms programmed Arduino ADK controller used to develop a DAST-PV system. The controller applied to position the solar panels to be directly perpendicular to the sun and gain the maximum sunlight. System performance was tested 
and compared to a stationary solar panel where the results showed an increase of output generation by $21.4 \%$ of the solar tracked system [7]. Another study developed a model using MATLAB/Simulink for solar power station automated dual-axis solar tracker of two solar PV types; monocrystalline and polycrystalline. The developed system compared with static modules where the results of the developed plant showed an optimum operating and proved the effectiveness tracking application for PV technology [8]. The performance of solar cooker integrated DAST-PV system was analyzed by Joshi and Jani [9]. The developed device placed the PV panels in the optimum position facing the sun using a controlled DC motor works automatically. The performance of the tracked system was compared with fixed PV panels in terms of electrical energy output and system efficiency. The results indicated an increase of about $7.5 \%$ in the efficiency of the panel for tracking mode comparing to the non-tracking one. The study also reported that the integrated cooker costs about three times more than the conventional solar cooker and around $4-5$ daily meals can be cooked for a small family using the tracking system. A comparison between a diffused reflectors PV system and a DAST-PV system was made by Ajayi et al. [10] to examine the performance of the proposed systems in terms of power output and system cost. The designed systems were placed at 23.50 with the horizontal to harvest the maximum solar radiation where the results showed better power output of the modified system with reflectors from about 11 am till $2 \mathrm{pm}$ while the PV tracked system was higher in the other times. On average, the output power of both systems was about the same during the day but, the modified system with collectors is the better option in terms of cost. A gridconnected DAST-PV system was installed in the cold region and compered to another stationary one closely located. The systems were simulated and examined during a year operation period on bases of conversion efficiency and energy generation capacity. The tracking PV system collected solar radiation as a total of $2173 \mathrm{kWh} / \mathrm{m}^{2}$ during the year of operation with an annual average conversion efficiency of $11 \%$ and a performance ratio of $0.82 \%$. Moreover, the results showed that the conversion efficiency and energy generation per capacity of the tracking system was higher than that of the stationary system by $0.3 \%$ and $40 \%$, respectively [11]. A new control methodology introduced to improve the PV sun tracker design based on an orientation efficiency chart. This methodology was feasible for the latitudes close to $30^{\circ}$ and costs $27 \%$ less than the traditional commercial systems which use slew drives. The system collection efficiency increased by $24 \%$ with respect to a fixed PV device [12]. The daily performance of a $40 \mathrm{~W}$ was analyzed experimentally against identical fixed PV system under clear sky, partially clear sky and cloudy sky conditions. The results reported that the tracking system can improve the power output by the range of $12-$ $20 \%$ compared to the fixed system. Furthermore, the study highlighted the variation of solar irradiation during the partially clear sky and cloudy sky conditions which need further research to limit the unnecessary energy used for tracking [13]. It is worth to mention that the modification using a tracking system has several drawbacks such as the higher cost and the need for maintenance. For the current work the Solarius software assumed that the yearly maintenance cost required for the system with dual-axis is around (0.6-1\%) of the capital cost which includes all system parts. The most part needs to be maintained in this system is the tracking sensor which depends on an extensive algorithm affected by weather conditions especially in the cloudy days when the tracking of the sun fluctuates. The other essential drawback of using the DAST system is the overheating of PV panels due to the excessive exposure to solar irradiance in the hot climate especially for crystalline silicon made panels [14]. This technology is feasible to be used in the cold climate and low solar radiation regions more than the hot areas. A recent study indicated that the tracking technology can improve the electricity by up to $39 \%$ in the cold climate while it doesn't exceed $8 \%$ in the hot climate. The study also reported that tracking technology isn't feasible if the energy needed for tracks ranging from $5 \%$ to $10 \%$ of the energy generated by this technology.

In the present work, a DAST-PV system proposed to overcome the electrical energy demand of a singlefamily house located in a hot area compared to a stationary PV system. A comparison was made for the two systems considering the total power output and the reduction of GHGs missions during the expected lifetime. The tracking method showed a good enhancement in power output compared to the stationary case as well as an impressive reduction in GHG emissions which shows excellent agreement with the same previous studies.

\section{Methodology}

The proposed PV systems designed using Solarius PV software to predict the total electricity demand needed for a single-family house of $117 \mathrm{~m}^{2}$ for 4-occupants located in Basra city $\left(30^{\circ} .5081 \mathrm{~N}\right.$ and $\left.47^{\circ} .7803 \mathrm{E}\right)$, Iraq. Solarius software can design different types of a photovoltaic system with a versatile tool that allows the technical design of the buildings. The software has a basic database of cities for various regions in the world including solar irradiation data as "Meteonorm" with the ability to define new locations.

The average monthly electricity consumption of building case study is variable within the year where the annual power demand reached $(17895.88 \mathrm{kWh})$, as shown in Figure 1. The demand for electricity is high during May, June, July and August because of the rising weather temperature and increasing refrigeration devices consumption while, January, February and December are the lesser energy consumption within the year.

The software has set to size a stationary and DAST- PV system which necessary to deliver electricity based 24 hours a day with different load profiles throughout the year. The daily average solar radiation available in house location is suitable and verified using "Meteonorm 7.1" data on the monthly average daily values of solar radiation on a horizontal plane, as shown in Figure 2. Depending on the available surfaces selected for the installed PV system, it is 


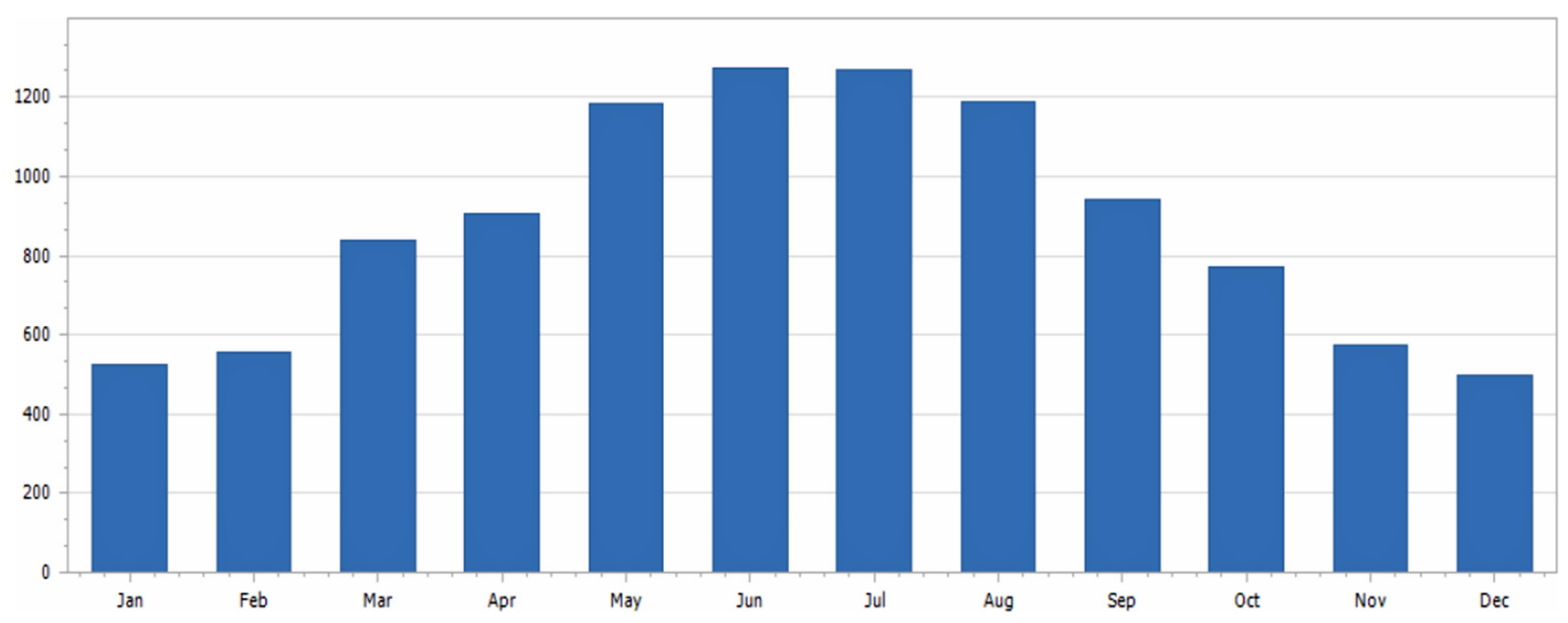

Fig. 1. Average monthly electricity consumption of the house (kWh).

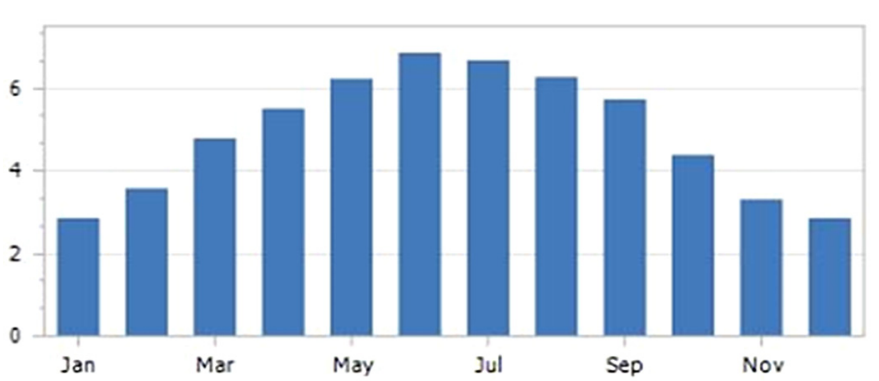

Fig. 2. Average daily solar radiation per month $\left(\mathrm{kWh} / \mathrm{m}^{2}\right)$.

possible to optimize system performance by Solarius PV software and define the electric consumption that customer needs.

\section{PV system configuration}

\subsection{Installation}

The installation and design principle use for a PV system normally aiming to maximize the collection of annual solar radiation. In most cases, the PV system must be optimally exposed to sunlight and set at the optimal orientation to the south to avoid shading. Therefore, the sizing of PV system was carried out by taking into account not only the financial aspects but also the availability of solar energy, morphological and environmental factors (shading and albedo). The effect of shading due to natural elements (trees, buildings, etc.) causes a reduction in solar gain and related payback time.

For the present research, shading coefficient and site morphology set to be 1.0 according to the solar energy diagram for Basra city. The architectural aspect of the building is necessary for system installation with different orientations that could be adapted as long as it adequately verified and evaluated. Energy losses due to such aspects could affect the cost of $\mathrm{kWh}$ produced and payback time period. In case of applications on pitched roofs, choosing the inclination and orientation is generally advisable to maintain the plane of modules in parallel or even with the level of the surface itself. Based on the fact that building shape is not altered, it is favorable to circulate the air between the module's rear and building envelope to limit temperature losses. The main advantage of using DAT for the PV system is harvesting the maximum amount of free solar radiation without waste to maximize the power extracting from the PV module to transfer the load and increase efficiency conversion of the PV system.

\subsection{System module}

The power output of PV systems is influencing by several factors such as solar radiation, weather temperature and electrical characteristic of PV modules, Table 1 shows the characteristics of the selected PV modules in this study. The modules selected for the tracking and stationary PV systems of type monocrystalline Si with $260 \mathrm{~W}$ peak power. Their minimum and maximum operating temperature points are -4 and $75^{\circ} \mathrm{C}$, respectively, with high operation quality and available at a competitive price. The PV modules designed with two strings to achieve the required current/voltage and connected in series to the inverter which enhance the reliability of the PV system with a reduction of power losses.

For the stationary PV system, each string has 20 arrays with total area of $67 \mathrm{~m}^{2}$ and fixed at a tilt angle of $26^{\circ}$ oriented toward the south. Distance between modules arranged automatically by the software with $1 \mathrm{~m}$ from the surface edge and there is no shading could effect. The PV system was working with maximum average daily solar radiation per month of $1912.46 \mathrm{kWh} / \mathrm{m}^{2}$ during operation as shown in Figure 3.

For the DAST-PV system, the software was automatically setting the optimal angles of modules depending on dedicated sensors deal with a light intensity of the sun. The 
Table 1. Electrical characteristics of PV modules in STC.

\begin{tabular}{lllllll}
\hline Conversion efficiency [\%] & $\mathrm{V}_{\mathrm{oc}}[\mathrm{V}]$ & $\mathrm{I}_{\mathrm{sc}}[\mathrm{A}]$ & $\mathrm{V}_{\max }[\mathrm{V}]$ & No. of cells & VMPP min [V] & VMMP max [V] \\
\hline 16.01 & 38 & 8.89 & 1000 & 60 & 250 & 850 \\
\hline
\end{tabular}

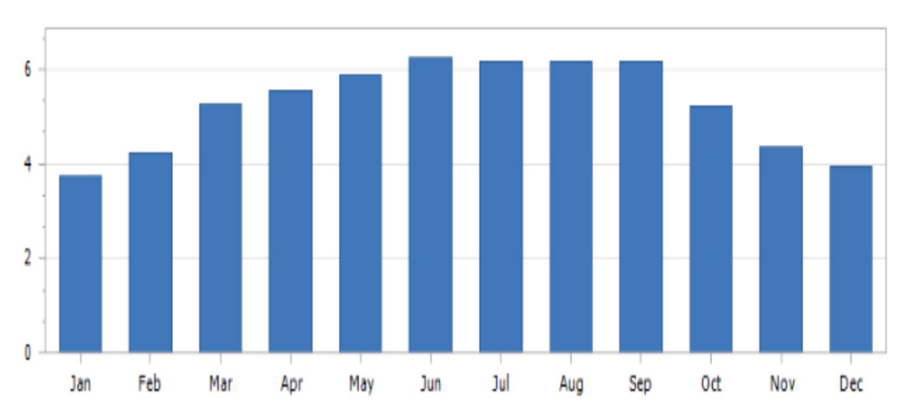

Fig. 3. Average daily solar radiation per month $\left(\mathrm{kWh} / \mathrm{m}^{2}\right)$ harvested by the stationary PV system.

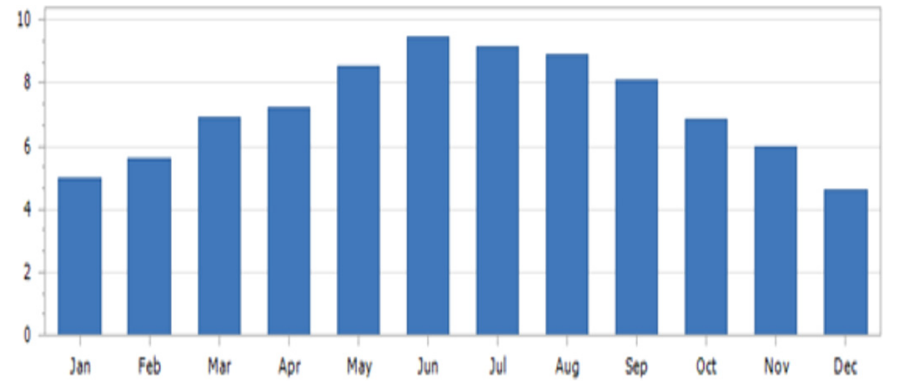

Fig. 4. Average daily solar radiation per month $\left(\mathrm{kWh} / \mathrm{m}^{2}\right)$ harvested by DAST- PV system.

Table 2. Technical specifications of the inverter.

\begin{tabular}{lllllll}
\hline Nominal voltage [V] & Phase type & Max. efficiency & V max [V] & I max [A] & $\begin{array}{l}\text { VMPP } \\
\max [\mathrm{V}]\end{array}$ & $\begin{array}{l}\text { VMPP } \\
\min [\mathrm{V}]\end{array}$ \\
\hline 230 & Single-phase & $91 \%$ & 900 & 20 & 850 & 250 \\
\hline
\end{tabular}

optimal angles of PV panels are important to harvest the largest amount of falling radiation and achieve a maximum power output of PV system during operation hours and contribute to reducing system losses. The tracking system was gained higher solar radiation according to the metrological data of the software where the maximum average daily solar radiation per month reached was $2626.81 \mathrm{kWh} / \mathrm{m}^{2}$ as shown in Figure 4.

\subsection{PV inverter}

The inverter is one of the important components of the PV system responsible for converting the current from DC to AC. Both the tracking-based and stationary PV systems used one single-phase inverter of the model (AEV-50-48) with a nominal power of $(10000 \mathrm{~W})$. The PV arrays have divided into two strings per module. Each string has $20 \mathrm{PV}$ panels to avoid damaging which might take place in the inverter due to overvoltage at the lowest temperatures. The electrical output parameters for each string are shown in Table 2. The typical sizing factor used is between $70 \%$ and $120 \%$ where the inverter sizing factor is the percentage ratio between the nominal power of the inverter and the power of the PV generator connected. For the case of MPPT sub-systems, sizing is verified for the MPPT subsystem as a whole. The proper selection of inverter size is important so if selected in big size, the capital cost and the produced energy of the PV system will increase as well.
The grid-tied inverter worked with proportionate efficiency and average daily solar radiation per month. The output power of $\mathrm{PV}$ is controllable to meet the load demand of the house when the grid is an interactive system of PV array. However, PV inverter has been selected to suit the change of PV array voltage due to the variety of the radiation and temperature which causes the low output voltage of the system.

\subsection{Energy storage}

Conservation and rationalization of energy are important in the continuity of energy sustainability to meet the shortage of energy consumed by different applications. Providing a storage system capable of storing excess energy is inevitable due to the varying intensity of solar radiation during the day. The storage system should be able to store energy to be used in the minimum-demand hours or low solar radiation and cloudy days. The external accumulation system allows the storage of excess energy from the PV production system or generator, to be reused when the generator is not producing enough energy. The batteries are essential elements of the PV system required to store the produced power by the PV system and in both tracking and stationary systems, 20 batteries were used for the two strings. The batteries of a model (MFV 350-Moura) which has a nominal capacity of 425 Ah. The state of charge (SOC) and depth of discharge (DOD) have taken into 


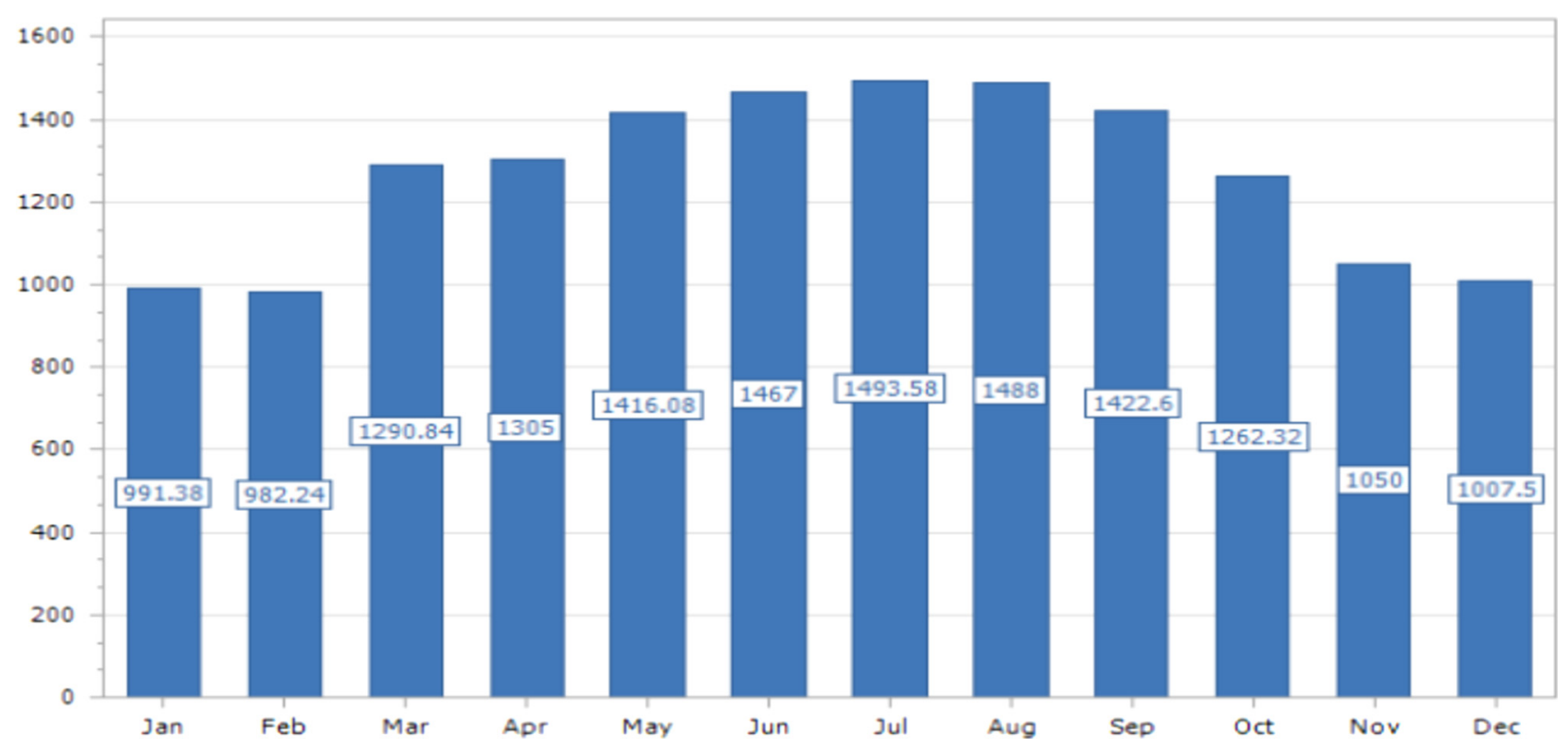

Fig. 5. Monthly energy production of the stationary PV system (kWh).

Table 3. Reduction of GHGs by the stationary PV system.

\begin{tabular}{lllll}
\hline Avoided atmospheric emissions & $\mathrm{CO}_{2}$ & $\mathrm{CH}_{4}$ & $\mathrm{~N}_{2} \mathrm{O}$ & Total GHG \\
\hline Specific atmospheric emissions $\left[\mathrm{kg} \mathrm{CO} \mathrm{CO}_{2} \mathrm{e} / \mathrm{kWh}\right]$ & 0.46254 & 0.00044 & 0.00236 & 0.46534 \\
Emissions avoided in one year $[\mathrm{kg} \mathrm{CO} 2 \mathrm{e}$ & 7019.76 & 6.68 & 35.82 & 7062.25 \\
Emissions avoided in 20 years $[\mathrm{kg} \mathrm{CO} 2 \mathrm{e}]$ & 129015.5 & 122.73 & 658.27 & 129796.46 \\
\hline
\end{tabular}

consideration to determine an appropriate operating ratio for regulation to make the battery charging/discharging according to the desired current. An accumulation system of Bidirectional production on the $\mathrm{AC}$ end has been selected for the external energy accumulation system. The external accumulation system allows the storage of excess energy from the PV production system or generator to be reused when the generator does not produce enough energy.

\section{Result and discussion}

The DAST and stationary PV systems have been connected to the main grid with a 'single-phase in low voltage' and worked under the same conditions. In both systems, the produced power depends on:

- The Installation of systems which mainly impacted by the latitude, longitude, incident solar radiation and surrounding temperature.

- Exposure of PV modules such as tilt and azimuth angle.

- Characteristics of PV modules such as power rating, temperature coefficient and decoupling losses or mismatch.
For the stationary $\mathrm{PV}$ system, there is acceptable stability of energy produced where the annual energy production was $15176.54 \mathrm{kWh}$ (equal to $1459.28 \mathrm{kWh} /$ $\mathrm{kW}$ ), resulting from 40 modules for two strings. Figure 5 shows the monthly energy production by the system. The stationary system overcome about $84.8 \%$ of house electricity demand and the rest was covered by the national grid. However, the variation of the amount of energy produced throughout the year is clear where January, February and December are the lower by energy production due to the fluctuation of solar radiation and frequent cloudy sky. On the other hand, it can be seen that May, June, July and August have the highest energyproduction due to the abundant of solar radiation and long sun hours during the day.

Adapting of the $\mathrm{PV}$ system reduce the polluting substances into the atmosphere and avoid emissions that contribute to increase the greenhouse effect, Table 3 indicates the reduction of GHGs of the stationary PV system during the year of study and, within the 20 years expected lifetime.

For the DAST-PV system, the output power produced was increased using the sensors which tracked the panels toward the sun and harvested the largest value 


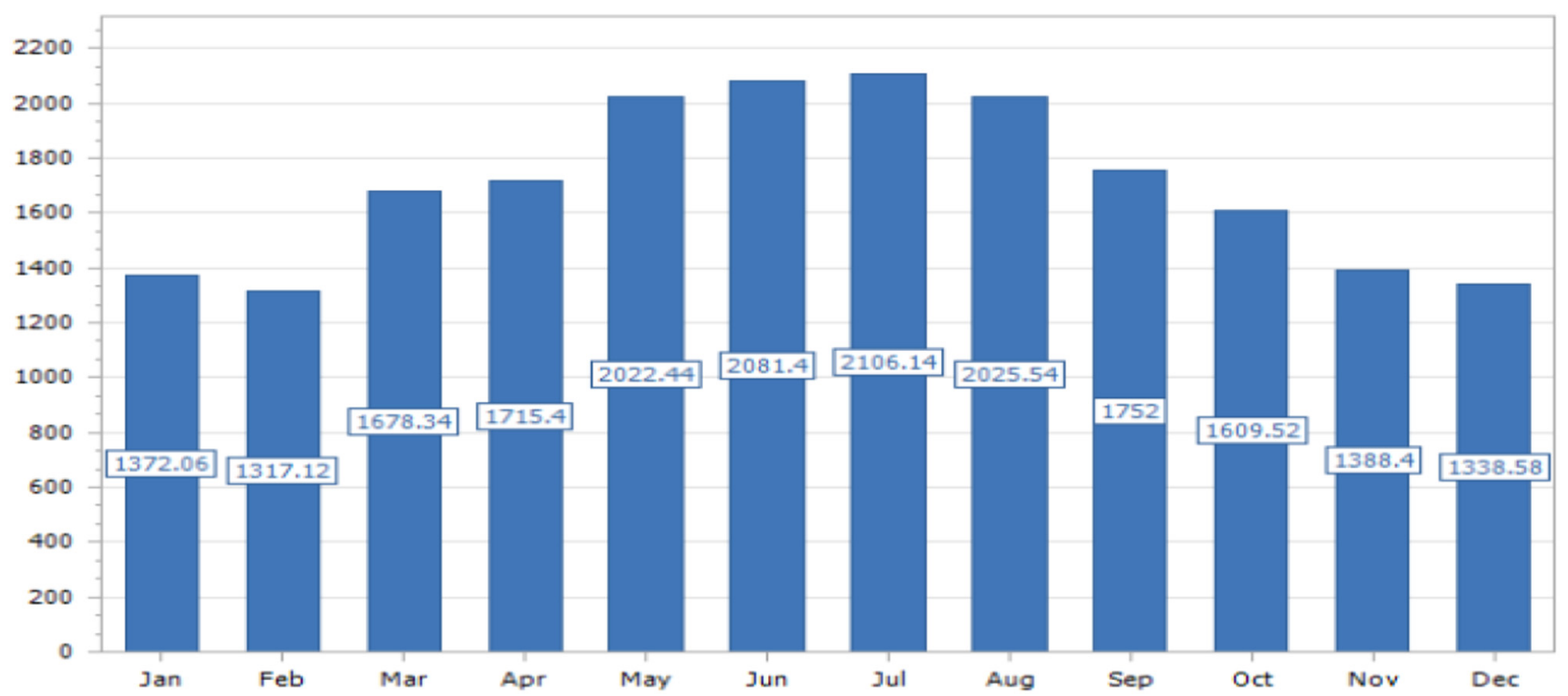

Fig. 6. Monthly energy production of DAST-PV system (kWh).

Table 4. Reduction of GHGs by DAST-PV system.

\begin{tabular}{lllll}
\hline Avoided atmospheric emission & $\mathrm{CO}_{2}$ & $\mathrm{CH}_{4}$ & $\mathrm{~N}_{2} \mathrm{O}$ & Total GHG \\
\hline Specific atmospheric emissions $\left[\mathrm{kg} \mathrm{CO} \mathrm{CO}_{2} \mathrm{e} / \mathrm{kWh}\right]$ & 0.46254 & 0.00044 & 0.00236 & 0.46534 \\
Emissions avoided in one year $[\mathrm{kg} \mathrm{CO} 2 \mathrm{e}]$ & 9439.03 & 8.98 & 84.16 & 9496.17 \\
Emissions avoided in 20 years [kg CO $2 \mathrm{e}]$ & $1,73,962.08$ & 165.49 & 887.60 & $1,75,016.07$ \\
\hline
\end{tabular}

of solar radiation reaching up to $2626.81 \mathrm{~kW} / \mathrm{m}^{2}$ where the radiation increased by about $37.3 \%$ compared to the stationary PV system. Annual energy production achieved by DAST is 20,406.94 $\mathrm{kWh}$ (equal to $1962.21 \mathrm{kWh} / \mathrm{kW}$ ), resulting from the same number installed for the stationary case; 40 modules. DAST system could overcome $100 \%$ of the electricity demand of the house and achieve a surplus power output up to $2511.06 \mathrm{kWh}$ which could be sold to the main grid. The maximum power produced was in the month of May, June, July and August where the solar radiation in maximum and long day hours while, the month of January, February and December recorded the lowest production of output power as shown in Figure 6 .

The PV system with DAST contributes to a significant reduction of polluting substances which resulting from the conventional power plants. Furthermore, the DAST system reduced the atmospheric emissions by up to $34.8 \%$ more than the stationary system during 20 years lifetime as shown in Table 4.

\section{Conclusion}

Adoption of the DAST- PV system to provide stable energy and maximize the power output is a good option for house level electricity demand. The main drawback of this technique is the high price due to sensors installation. In the present research, a comparison was made between a stationary and tracking PV system in terms of power output production and the relevant reduction of GHGs emissions. The tracking PV system showed a significant increase in harvested solar radiation by about $37.3 \%$ more than the stationary PV system. Power production is fluctuating during the year where is proportional to the abundance of solar radiation and long day hours. The month of July was the biggest in power production due to the availability of solar radiation in most day hours in opposite to the month of February when the winter season significantly affects productivity. Annual power production achieved by the tracking PV system had overcome up to $100 \%$ of the electricity demand of the single-family house case study with a $2511.06 \mathrm{kWh}$ surplus, at the same time, the stationary PV system can overcome only $84.8 \%$. Therefore, the DAST- PV system could achieve better energy stability other than the stationary PV system. Using a tracking PV system is a very useful indicator to measure the amount of fuel saved when using a renewable energy source. As a result, more reduction of GHGs emissions could be achieved over the 20 years lifetime of the PV system. 


\section{References}

1. SEIA, Solar Energy Industries Association, Solar Industry Research Data. https://www.seia.org/solar-industry-re search-data (accessed on 5 December 2019)

2. N.I.B. Jallo, Should Iraqis go solar on household level? J. Asian Sci. Res. 3, 903 (2013)

3. M.H.R. Alktranee, Q. Al-Yasiri, Evaluation of an off-grid photovoltaic technology for household application in Iraq, in Proceeding of the Third International Scientific Conference for Renewable Energy and Applied Research (ISCFREAR), Southern Technical University, Basra, Iraq, 14th-15th March 2018, J. N. U. C. 6, 118 (2018)

4. E. Lorenzo, M. Pérez, A. Ezpeleta, J. Acedo, Design of tracking photovoltaic systems with a single vertical axis, research and applications, Prog. Photovol. 10, 533 (2002)

5. S.V. Mitrofanov, D.K. Baykasenov, M.A. Suleev, Simulation model of autonomous solar power plant with dual-axis solar tracker, in International Ural Conference on Green Energy, UralCon (2018), doi: 978-1-5386-4936-7/18/\$31.00

6. S. Adarsh, A. Anand, J. Singla, Increasing the efficiency of a PV system using dual axis solar tracking, in Proceedings of 11th IRF International Conference, 15th February 2015, Bengaluru, India, 2015

7. A.K. Suria, R.M. Idris, Dual-axis solar tracker based on predictive control algorithms, in IEEE Conference on Energy
Conversion (CENCON), 19-20 October 2015, Johor Bahru, Malaysia, 2015

8. S.V. Mitrofanov, A.Y. Nemaltsev, D.K. Baykasenov, Primary testing of automated dual-axis solar tracker in the climatic conditions of the Orenburg region as the prospects for the establishment of a hardware-software complex, Int. Sci. J. Alt. Energy Ecol. 7-9, 43 (2018)

9. S.B. Joshi1, A.R. Jani, Certain analysis of a solar cooker with dual axis sun tracker, in Nirma University International Conference on Engineering (NUiCONE) 28-30 November 2013, IEEE, Ahmedabad, India, 2013

10. A.B. Ajayi, O.A. Majekodunmi, A.S. Shittu, Comparison of power output from solar PV panels with reflectors and solar tracker, J. Energy Tech. Pol. 3, 7 (2013)

11. W. Choi, M.B. Pate, R.D. Warren, R.M. Nelson, An experimental performance evaluation of a cold-region photovoltaic system with tracking, J. Sol. Energy Eng. 139, 3 (2017)

12. J. Ruelas, F. Muñoz, B. Lucero, J. Palomares, PV tracking design methodology based on an orientation efficiency chart, Appl. Sci. 9, 894 (2019)

13. G.C. Lazaroiu, M. Longo, M. Roscia, M. Pagano, Comparative analysis of fixed and sun tracking low power PV systems considering energy consumption, Energy Conv. Manag. 92, $143(2015)$

14. S.A. Sharaf Eldin, M.S. Abd-Elhady, H.A. Kandil, Feasibility of solar tracking systems for PV panels in hot and cold regions, Renwe. Energy 85, 228 (2016)

Cite this article as: Mohammed H.R. Alktranee, Qudama Al-Yasiri, Mortda. M. Sahib, Power output enhancement of gridconnected PV system using dual-axis tracking, Renew. Energy Environ. Sustain. 5, 8 (2020) 